\title{
A Bi-Objective Optimization Approach for Inflight Food Waste Reduction
}

\author{
Lay Eng Teoh ${ }^{1 *}$ and Jaspreet kaur A/P Inderjit Singh ${ }^{1}$ \\ ${ }^{1}$ Lee Kong Chian Faculty of Engineering and Science, Universiti Tunku Abdul Rahman, 43000 \\ Kajang Selangor, Malaysia
}

\begin{abstract}
For airline industry, an excess of inflight food waste has been highlighted as one of the crucial concerns that affecting airline's profit margin and operations. Furthermore, it may result in environmental issue if excessive food waste is not handled with care. As such, ensuring an optimal inflight catering service is particularly important to airlines. However, the existing literatures focusing on the reduction of inflight food waste is very limited. Correspondingly, this paper develops a bi-objective inflight food waste reduction model, with the aim to minimize inflight food waste while maximizing passengers' expectation towards inflight catering service. In particular, an optimal strategy of offering inflight meals (comprise standard and light meals) is proposed appropriately to meet the demand of passengers under uncertainty. By examining some international flights, the results of an illustrative case study show that the developed model is viable to reduce airline's inflight food waste to a greater extent. Besides, the airline would have greater flexibility to meet the expectations of the passengers in a better manner. It is anticipated that the developed model would reveal some useful insights to the airlines in providing inflight catering services profitably and environmentally.
\end{abstract}

\section{Introduction}

In a highly competitive environment of airline industry, the delivery of high quality service to passengers is vital for airline's survival, competitiveness, profitability and sustainable growth [1]. This necessitates the focus of airlines on cost reduction in order to achieve efficient operations [2]. Correspondingly, inflight meal service ought to be handled with care as it involves high volumes, significant costs and it also has direct impact on customer service [3]. As reported by $\mathrm{Li}$ et al. [4], a flight could produce about $134-243 \mathrm{~kg}$ of food waste while the food waste of meals ranged $23-51 \%$ for different types of meals. Approximately, there is a total amount of 725 tonnes (per annum) generated from organic waste including food waste [5]. In addition, it was found that food waste is related not only to economic performance but also environmental and societal impacts [6-8]. Furthermore, Niu et al. [9] revealed that passengers would prefer to choose airlines that supported environmental protection. Rosskopf et al. [10] also highlighted that environment-friendly airlines can build a greener image and thus attract and retain customers in the future. Thus,

\footnotetext{
* Corresponding author: teohle@utar.edu.my
} 
this motivates the formulation of an optimal inflight food waste reduction model (i.e. as a green approach) that could provide a proper decision-making to airlines in handling inflight catering service, at a sustainable and environmental manner.

Practically, it is crucial for the airlines to confirm the meals order from the caterers, latest 4-6 hours before aircraft departure. This is particularly important to meet the needs of passengers under uncertainty in view of the fact that the demand level of passengers is varying from time to time $[3,11]$ and therefore necessary adjustments are often required. As such, a well-developed model is certainly needed to determine the optimal quantity of inflight meals. It is significant to note that inflight meals may vary for different flight time (morning, afternoon, eveningand night), flight type (short, medium and long-haul), aircraft type (small, medium, large and jumbo) as well as passenger's class (first, business and economy class). Apparently, there are many relevant factors that could affect the inflight catering services of the airlines. Furthermore, different types of airline may possess different business structures. As such, it is rather significant, yet complicated, to deal with inflight food waste reduction.

There are some studies which are related to inflight catering service of airlines. With regard to the service quality of airline in terms of inflight meal services, Suki [1] examined the effects of airline service quality (including inflight catering) on customer satisfaction. They performed their analysis with the aid of structural equation modeling. More recently, Farooq et al. [12] assessed the quality of service provided by the airline and its impact on customer satisfaction, by using convenience sampling method and variance based structural equation modeling. In overall, their results show that inflight catering has a positive, direct and significant impact on customer satisfaction. In addition to the impact of inflight meal on overall airline's service quality, Romli et al. [13] also showed that the offering of inflight meals service does significantly affect the passengers' choice of airlines. Besides, Mayer et al. [14] conducted a quantitative survey to analyze air traveller perceptions of different airlines with regard to green image, and also how passengers perceive different measures that airlines can introduce to reduce environmental impact. Their results revealed that the reduction of waste on board (by not offering free food) is an effective measure. With the aim to provide meal quantity that closely matches the final passenger load, Goto [3] modeled meal ordering process as a finite-horizon Markov decision process. The results show that the developed model would yield a substantial amount of savings while reducing the number of short catered flights for the airline. In addition, Teoh and Khoo [15] developed a single-objective optimization model that aims to minimize total inflight food waste by determining the optimal quantity of inflight meals. In contrast to Teoh and Khoo [15], this study proposed a bi-objective mathematical model by considering passengers' expectations in addition to cost minimization that corresponds to optimal quantity of inflight meals. Besides, budget and penalty constraints are included in the bi-objective mathematical model in order to assure the benefits of supply (airline) and demand (passengers). Concisely, although the afore-mentioned studies are relatively related to inflight catering, it is apparent that there is no documented study that explicitly optimize the quantity of inflight meals, by considering both aspects of supply (i.e. airline) and demand (i.e. passengers) under uncertainty. Therefore, a well-developed model is indeed required.

For the current practice, inflight food waste is kept for food recycling or processed as lightweight materials for food packaging. In contrast to the mitigation actions taken after flight operation, this study aims to propose a green approach to reduce inflight food waste before flight operations, by capturing passenger's choice explicitly towardsinflight meals. Instead of a typical (standard) inflight meal, this study aims to reduce the inflight food waste, by offering the option of serving a lightmeal in addition to regular standard meal. Specifically, light meal refers to a similar meal with standard meal but possesses a lower food weight, i.e. light meal has a smaller portion compared to a standard meal.For the 
passengers, they could select their favorable meals, i.e. either standard or light meal, during the process of flight booking (i.e. reserved). For those do not opt for any meal type during the flight booking process (i.e. unreserved), they can still choose their favorable size of meal (either standard or light)at a later time by updating their meal choice before aircraft departure or during their flight. However, the choice of meal is largely depending on the availability of the loaded meals of a particular flight. As such, how to properly quantify the optimal quantity of inflight meals optimally under uncertainty is important.

The remainder of the paper is organized as follows. Section 2 presents the formulation of the bi-objective optimization model for inflight food waste reduction. Section 3 illustrates the case study with a comprehensive discussion on the resultant findings. Section 4 concludes the paper with some suggestions for further research.

\section{Formulation of bi-objective inflight food waste reduction model}

This section presents the formulation of bi-objective optimization model to reduce inflight food waste. The notations used for the model formulation are listed as below:

\begin{tabular}{|c|c|}
\hline Component & Description \\
\hline$n$ & Aircraft type \\
\hline$r$ & Flight route \\
\hline$i$ & Meal type \\
\hline$j$ & Meal order (sequence) \\
\hline$k$ & Passenger's seating order (for which $k=1,2, \ldots S E A T_{n}$ ) \\
\hline$c$ & Passenger's class (first, business, economy) \\
\hline$t$ & Flight time (morning, afternoon, evening, night) \\
\hline$\alpha_{n, r, i, j, c, t}^{R S}$ & Portion of reserved standard meal \\
\hline$\alpha_{n, r, i, j, c, t}^{U S}$ & Portion of unreserved standard meal \\
\hline$\beta_{n, r, i, j, c, t}^{R L}$ & Portion of reserved light meal \\
\hline$\beta_{n, r, i, j, c, t}^{U L}$ & Portion of unreserved light meal \\
\hline$\alpha$ & Probability to meet passenger's onboard meals request \\
\hline$\mu$ & Average number of passengers requested onboard meal \\
\hline$\sigma$ & $\begin{array}{l}\text { Standard deviation of the number of passengers requested onboard } \\
\text { meal }\end{array}$ \\
\hline$A d d_{\%}$ & Additional percentage of maximum quantity of meals \\
\hline$M A X_{n, r, i, j, c, t}$ & Maximum quantity of meal loaded on aircraft \\
\hline$M I N_{n, r, i, j, c, t}$ & Minimum quantity of meal loaded on aircraft \\
\hline$P_{\$}$ & Penalty cost \\
\hline$P_{\$}^{\operatorname{Max}}$ & Maximum penalty cost \\
\hline$S$ & Cost allocated for inflight meal \\
\hline$S E A T_{n}$ & Aircraft capacity \\
\hline$w_{c}$ & Weightage for inflight food weight (in terms of cost) \\
\hline$T_{\text {flight }}$ & Cost of inflight meals \\
\hline$w_{\text {diff }}$ & Weightage for the weight difference of expected and served meal \\
\hline
\end{tabular}


$T_{d i f f}$
$W_{\text {expected }}^{k}$
$W_{\text {served }}^{k}$
$W_{n, r, i, j, c, t}^{R L}$
$W_{n, r, i, j, c, t}^{R S}$
$W_{n, r, i, j, c, t}^{U L}$
$W_{n, r, i, j, c, t}^{U S}$
$y_{i}$

$\underline{\text { Decision variable }}$

$Q_{n, r, i, j, c, t}^{R S}$

$Q_{n, r, i, j, c, t}^{R L}$

$Q_{n, r, i, j, c, t}^{U S}$

$Q_{n, r, i, j, c, t}^{U L}$
Cost of weight difference for expected and served meal

Weight of expected meal for passenger $k$

Weight of served meal for passenger $k$

Weight of reserved light meal

Weight of reserved standard meal

Weight of unreserved light meal

Weight of unreserved standard meal

Cost of inflight meal ( $i=1$ for standard meal; $i=2$ for light meal)

In order to achieve operational and environmental sustainability, the aim of the proposed model is to minimize inflight food waste as well as to meet passengers' expectations on inflight catering. To do this, the passenger's choice on inflight meal which would constitute the total weight of onboard food will be determined optimally. In order to capture the choice of passengers towards their preferable inflight meals, their selection of meals during the whole flight could be categorized accordingly as reserved standard meal, reserved light meal, unreserved standard meal and unreserved light meal. As such, the objective function of the formulated bi-objective inflight food waste reduction model can be expressed as below:

$$
\text { Minimize Total cost, } T C=w_{c} T_{\text {flight }}+w_{\text {diff }} T_{\text {diff }}
$$

for which



Objective 2: $T_{\text {diff }}=\sum P_{\mathrm{s}}\left|W_{\text {expected }}^{k}-W_{\text {served }}^{k}\right|$

As shown above, the total cost of inflight meals (for objective 1) is contributed by the respective cost of inflight meals with the corresponding weight and quantity. It is anticipated that having light meal as an additional option could lead to cost savings of the airlines. Besides, the total cost for objective 2 is contributed by the penalty cost and the difference between the expected and served meal, in order to assure that passengers' expectations are met satisfactorily. With the aid of weighted-sum method [16], these objectives are then combined to form objective function (1) for the bi-objective optimization model. In order to obtain the optimal solution realistically, objective function (1), i.e. the minimization of the total cost, $T C$ is optimized subject to seven practical constraints as described below:

Demand constraint This constraint ensures that passengers' demand is fulfilled satisfactorily. Particularly for low-cost carrier (LCC), it is assumed that the passengers' demand for inflight meals follows a normal distribution in which $F^{-1}(1-\alpha)$ is the inverse 
cumulative probability of $(1-\alpha)[15]$. As such, the demand constraint for LCC can be expressed as below:

$$
\operatorname{MIN}_{n, r, i, j, c, t} \geq F^{-1}(1-\alpha) \sigma+\mu
$$

On the other hand, the demand constraint of full-service carrier (FSC) is bounded between $M I N_{n, r, i, j, c, t}$ and $M A X_{n, r, i, j, c, t}$, as showed below. The constraint is bounded to ensure that meals boarded on the flight meets the minimum quantity of meals as well as additional requests of meals (if any). Thus, the demand constraint for FSC can be expressed as below:

$$
M I N_{n, r, i, j, c, t} \leq \sum Q_{n, r, i, j, c, t}^{R S}+Q_{n, r, i, j, c, t}^{R L}+Q_{n, r, i, j, c, t}^{U S}+Q_{n, r, i, j, c, t}^{U L} \leq M A X_{n, r, i, j, c, t}
$$

for which $M A X_{n, r, i, j, c, t}=\left(1+A d d_{\%}\right)\left(\sum Q_{n, r, i, j, c, t}^{R S}+Q_{n, r, i, j, c, t}^{R L}+Q_{n, r, i, j, c, t}^{U S}+Q_{n, r, i, j, c, t}^{U L}\right)$. In particular, $A d d_{\%}$ could be determined by performing forecasting or extrapolation based on the past records (for additional meals requested by the boarding passengers). On the other hand, the element of $M I N_{n, r, i, j, c, t}$ could be determined according to the load factor of a particular flight.

\section{Meals choice constraint}

This constraint assures that each passenger (individual passenger) of FSC will be served only one meal (either standard or light meal but not both) or the passenger chooses not to have any meal (if both binary variables are zero). Meals choice constraint could be formed as below:

$$
B_{n, r, i, j, c, t}^{\text {standard }(k)}+B_{n, r, i, j, c, t}^{\text {light }(k)} \leq 1
$$

where

$B_{n, r, i, j, c, t}^{\text {standard }(k)}=\left\{\begin{array}{l}1, \text { if passenger } k \text { choose standard meal } \\ 0, \text { otherwise }\end{array}, B_{n, r, i, j, c, t}^{\operatorname{light}(k)}=\left\{\begin{array}{l}1, \text { if passenger } k \text { choose light meal } \\ 0, \text { otherwise }\end{array}\right.\right.$

This constraint is not applicable to LCC passengers because they have the flexibility to buy any onboard meals (with any quantity).

Meal availability constraint This constraint ensures that the type of meals (standard and light) is offered accordingly to the passengers. Under certain circumstances, some aircraft of a particular flight may not offer a certain type of meal due to some operational issues (e.g., the flight duration is too short (less than one hour)). As such, meal availability constraint can be defined as below:

$$
\begin{aligned}
M_{n, r, j, c, t}^{\text {standard }} & =\left\{\begin{array}{l}
1, \text { if standard meal } i \text { is offered subject to pre-determined criteria, } C \\
0, \text { otherwise }
\end{array}\right. \\
M_{n, r, i, j, c, t}^{\text {light }} & =\left\{\begin{array}{l}
1, \text { if light meal } i \text { is offered subject to pre-determined criteria, } C \\
0, \text { otherwise }
\end{array}\right.
\end{aligned}
$$

where $C$ refers to a pre-determined criteria defined by the airlines or caterers.

Weight of meal constraint This constraint assures that the total weight of meals to be loaded on aircraft is fitted on varying aircraft type (with different aircraft specification). This constraint would also assure that the total quantity of meals (with a prescribed weight) would not be overloaded on aircraft. As such, weight of meal constraint can be expressed by:

$$
\sum Q_{n, r, i, j, c, t}^{R S}\left(W_{n, r, i, j, c, t}^{R S}\right)+Q_{n, r, i, j, c, t}^{R L}\left(W_{n, r, i, j, c, t}^{R L}\right)+Q_{n, r, i, j, c, t}^{U S}\left(W_{n, y, j, j, c, t}^{U S}\right)+Q_{n, r, j, j, c, t}^{U L}\left(W_{n, r, j, j, c, t}^{U L}\right) \leq\left(1+A d d_{\%}\right) W_{n, r, i, j, c, t}
$$


particular flight is contributed by the standard and light meals (either reserved or unreserved). Thus, meals portion constraint can be defined as below:

$$
\alpha_{n, r, i, j, c, t}^{R S}+\beta_{n, r, i, j, c, t}^{R L}+\alpha_{n, r, i, j, c, t}^{U S}+\beta_{n, r, i, j, c, t}^{U L}=1
$$

\section{Budget constraint}

This constraint ensures that the total cost of inflight meals does not exceed the cost allocated by the airlines. By considering the cost of standard and light meals, budgetconstraint can be formed as below:

$$
\sum y_{1}\left(Q_{n, r, i, j, c, t}^{R S}+Q_{n, r, i, j, c, t}^{U S}\right)+y_{2}\left(Q_{n, r, i, j, c, t}^{R L}+Q_{n, r, i, j, c, t}^{U L}\right) \leq S
$$

Penalty constraint This constraint ensures that the total penalty incurred for the weight difference of inflight meal does not exceed the allocated limit as predetermined by the airlines. It is also important to meet the expectation of the passengers. Penalty constraint can be formed as below:

$$
\sum P_{\mathrm{S}}\left|W_{\text {expected }}^{k}-W_{\text {served }}^{k}\right| \leq P_{\mathrm{S}}^{\text {Max }}
$$

In summary, the developed bi-objective inflight food waste reduction model, as presented above, can be solved by optimizing objective function (1), subject to constraints (3)-(9) for FSC and constraints (2), (5)-(9) for LCC. There are 2 stages, namely initial and updating stages in determining the optimal quantity of standard and light meals (either reserved or unreserved). Basically, initial stage plays the role to quantify the quantity of meals (standard and light) at the time the passengers purchase their flight tickets. Subsequently, the optimal quantity of standard and light meals is determined from time to time if there is any updating of meal choice from the passengers, i.e. at least 24 hours before the departure time of flight [17]. In particular, CPLEX optimization software is used to generate the optimal solutions.

\section{An illustrative case study}

In order to examine the applicability of the developed model, an illustrative case study comprises 219 international long-haul flightsis outlined, by considering the aircraft operations of Malaysia Airlines from Kuala Lumpur International Airport (KLIA). The daily data of these flights is compiled according to theaircraft operations of Malaysia Airlines on 15th January 2018. For brevity, the complete data compiled for 219 flights are not displayed in this paper. Some other data inputs are listed as below:

- Aircraft type, $n=1,2, \ldots, 11$ (for 11 aircraft types)

- Flight route, $r=1,2, \ldots, 219$ (for 219 long-haul flights)

- Passenger's class, $c=1,2$ (for which 1 for first/business class and 2 for economy)

- Meal order, $j=1,2,3$ (for first, second and third meal)

- Flight time, $t=1,2,3,4$ (for morning, afternoon, evening and night)

- Pre-determined criteria, $C=$ block time of flight exceeds one hour

- Weightage for inflight food weight (in terms of cost), $w_{c}=0.5$

- Weightage for the weight difference of expected and served meal, $w_{\text {diff }}=0.5$

- Additional percentage of maximum quantity of meals, $A d d_{\%}=10 \%$

- Estimated meal cost, $y_{i}=\mathrm{RM} 0.10 / \mathrm{gram}$

- Penalty cost, $P_{\mathrm{s}}=\mathrm{RM} 0.10 / \mathrm{gram}$

- Maximum penalty cost, $P_{\mathrm{s}}^{\text {Max }}=\mathrm{RM} 1,000$ (per flight) 
- Cost allocated for inflight meal, $S=$ RM10,000 (per flight)

Besides, Tables 1 and 2 show the weights and costs of respective meal.

Table 1. The weight of respective inflight meal [18].

\begin{tabular}{|c|c|c|}
\cline { 2 - 3 } \multicolumn{1}{c|}{} & First/business class & Economy class \\
\hline Weight of standard meal (gram) & 308 & 280 \\
\hline Weight of light meal (gram) & 246 & 224 \\
\hline Weight difference of standard and light meal & 62 & 56 \\
\hline
\end{tabular}

Table 2. The cost of respective inflight meal [19].

\begin{tabular}{|c|c|}
\cline { 2 - 2 } \multicolumn{1}{c|}{} & Cost per meal (RM) \\
\hline Standard meal & 20 \\
\hline Light meal & 15 \\
\hline
\end{tabular}

From the data input as listed above, model optimization is performed by capturing the initial meal preference of passengers (initial stage), followed by three updating stages in order to determine the optimal quantity of inflight meals from time to time. According to Goto [3], there are three key decision points for inflight meals production prior to aircraft departure. However, the decisions to alter production quantity of inflight meals may be made at intermediate time intervals (if necessary).

\subsection{Results discussion}

As presented below, the resultant findings can be discussed from various aspects, i.e. reserved and unreserved meals, standard and light meals, meal types, passengers' classes, cost savings and the corresponding food waste reduction.

In average, the results in Fig. 1 show that there is a higher tendency for the passengers to reserve their meals, i.e. in average 58\%. Besides, Fig. 2 shows that the passengers tend to opt for a light meal (up to 50.3\%) compared to a standard meal (49.7\%). For the airlines, this provides an insightful information of offering light meal (in addition tostandard meal) for a particular flight. In addition, the results in Fig. 3 show that there are more passengers (about 58\%) who prefer to reserve their meals for all meal types (for breakfast, lunch, dinner, supper). Besides, the results also show that the passengers tend to choose light meals for breakfast and supper. For lunch and dinner, most of the passengers prefer standard meals. Concisely, the results show that the meal that is served at different time (morning, afternoon, evening or night) would gain different reaction from the passengers and hence the airlines may plan accordingly of offering adequate quantity of inflight meals.

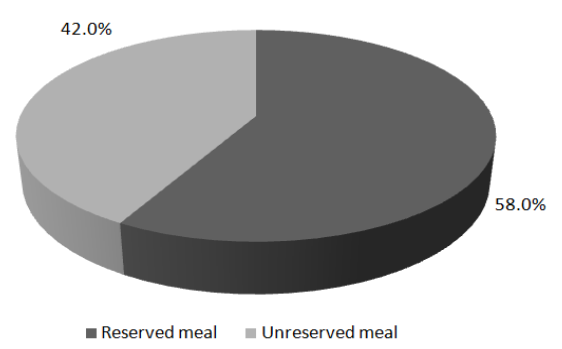

Fig. 1. The results of reserved and unreserved meals. 


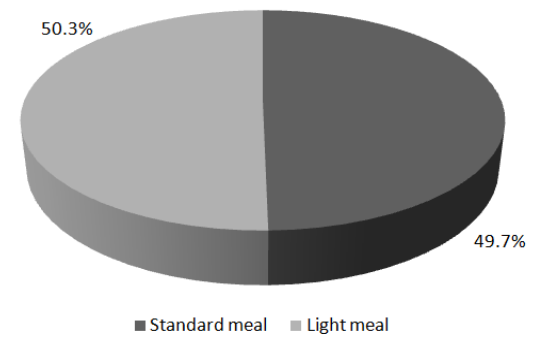

Fig. 2. The results of standard and light meals.

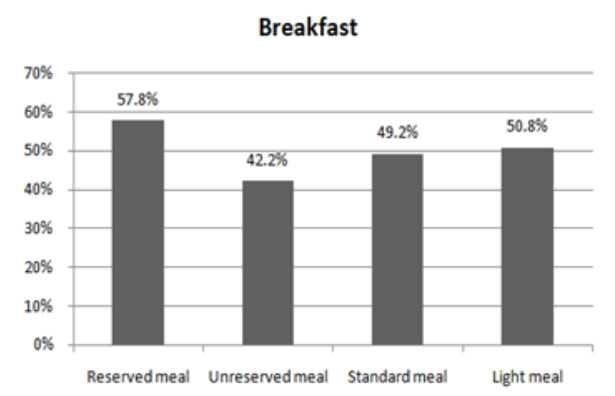

Dinner



Lunch



Supper



Fig. 3. The results of different meal types.

Besides, the results in Fig. 4 reveal that the passengers (both first/business and economy classes) prefer to reserve light meal, except the third meal (for which the passengers prefer to reserve standard meal). For unreserved meals, the passengers also show the tendency towards light meal, except the economy-class passengers who prefer unreserved standard meal as their third meal. Although the results in Fig. 4 shows that the percentage of first/business-class passengers to reserve inflight meals is higher than economy-class passengers, in fact there are more economy-class passengers to take reserve meals (in view of the fact that the number of seats of economy class is much more than the number of seats of first/business class).

As displayed in Table 3, the results show that the total weight reduction of inflight meals (for all 219 long-haul flights) is $6,106 \mathrm{~kg}$ for daily flight operations. In average, each long-haul flight could reduce about $28 \mathrm{~kg}$ of food waste (per day). For annual flight operations, the total annual weight reduction of meals is approximately to be 1,148 tonnes (per annum), i.e. about 5.2 tonnes(per flight). This, in fact, would constitute a total of saved cost up to RM524,023 (for each flight per annum) and up to a cost savings of RM115 millions per year. Besides, it is estimated that the extent of food weight reduction is about 
$158 \%$ in comparison to the reported annual amount of waste at 725 tonnes[5]. In overall, the results inferred the benefits of offering light meals in terms of cost savings as well as food waste reduction.


Fig. 4. The results of different passenger classes.

Table 3. The results of inflight food waste reduction (for 219 long-haul flights).

\begin{tabular}{|l|c|}
\hline Total weight reduction of meals (kilogram/day) & 6,106 \\
\hline Average of weight reduction of meals (kilogram/flight/day) & 28 \\
\hline Total annual weight reduction of meals (kilogram/annum) & $1,147,611$ \\
\hline Average of annual weight reduction of meals (kilogram/flight/annum) & 5,240 \\
\hline Total saved cost (RM/annum) & $114,761,100$ \\
\hline Average of total saved cost (RM/annum/flight) & 524,023 \\
\hline Extent of food weight reduction (per annum) & $158 \%$ \\
\hline Note: Average optimal quantity of inflight meals is 977 (total for first, second and third meals). \\
\hline
\end{tabular}

\section{Conclusions}

This paper deals with the formulation and optimization of a bi-objective inflight food waste reduction model which aims to maximize passengers' expectation while reducing food waste resulted from inflight catering services. By providing the choice of standard and light meal to the passengers, the results of illustrative case study show that there is a mixed 
preference towards the meals selection among the passengers. The preference of meal size (for standard and light meal) could be affected by several factors, including flight type, meals type and passenger's class. Besides, the findings highlight that the option of offering light meal (in addition to standard meal) would contribute a substantial cost savings to the airline, i.e. approximately RM115 millions per annum. In particular, the airline may consider to offer more light meals for inflight breakfast and supper (in comparison to lunch and dinner). For further analysis, more operating networks of different airlines can be considered. The developed model could be extended too by considering the respective load factor of flights in order to perform more realistic analysis.

\section{References}

1. Suki, Res. in Transport. Business and Manag., 10, 26-32 (2014)

2. T. Boetsch, T. Bieger, A. Wittmer, Transport J., 50, 251-270 (2011)

3. J. H. Goto, A Markov decision process model for airline meal provisioning. Thesis of Master of Science (Business Administration). The University of British Columbia (1995)

4. X.D. Li, C.S. Poon, S.C. Lee, S.S. Chung, F. Luk, Resources, Conservation and Recycling, 37, 87-99 (2003)

5. A. M. El-Mobaidh, M.A.R. Taha, N.K. Lassheen, Waste Manag., 26, 587-591 (2006)

6. M. Bourlakis, G. Maglaras, E. Aktas, D. Gallear, C. Fotopoulos, Int. J. of Prod Econ, 152, 112-130 (2014)

7. K. Govindan, A. Jafarian, R. Khodaverdi, K. Devika, Int. J. of Prod Econ, 152, 9-28 (2014)

8. W. A. Rijpkema, R. Rossi, J.G.A.J.van der Vorst, Int. J. of Phys. Distribution Logistic Manag., 44(6), 494-510 (2014)

9. S-Y. Niu, C-L.Liu, C-C.Chang, K-D. Ye, J. of Air Transport Manag., 55, $84-91$ (2016)

10. M. Rosskopf, S.Lehner, V. Gollnick, J. of Air Transport Manag., 34, 109-115 (2014)

11. H.L. Khoo, L.E. Teoh, Transport. Res. Part D, 33, 166-185 (2014)

12. M.S. Farooq, M. Salam, A. Fayolle, N. Jaafar, K. Ayupp, J. of Air Transport Manag., 67, 169-180 (2018)

13. F. I. Romli, K.A. Rahman, F.D. Ishak, IOP Conference Series: Materials Science and Engineering (2016)

14. R. Mayer, T. Ryley, D. Gillingwater, J. of Transport Geography, 22, 179-186 (2012)

15. L.E. Teoh, H.L. Khoo, 28th European Conference on Operational Research, Poland (2016)

16. M. Caramia, P. Dell'Olmo, Multi-objective Management in Freight Logistics. London: Springer Verlag (2008)

17. AirAsia Berhad, http://www.airasia.com.my (2013)

18. E. Editor, http://www.eturbonews.com/45931/waste-not-what-happens-leftover-airlinefood (2017)

19. P. Morrell, Res. in Transportation Econ., 24(1), 61-67, 2008 